\title{
PENINGKATAN PRODUKTIVITAS MESIN SANGRAI BIJI KOPI DI UKM KABUPATEN KEDIRI
}

\author{
Eko Yohanes Setyawan ${ }^{1 *}$, Basuki Widodo², Ahmad Dony Mutiara Bahtiar ${ }^{3}$, \\ Irmalia Suryani Faradisa ${ }^{4}$ \\ ${ }^{1,2}$ Teknik Mesin, Institut Teknologi Nasional Malang \\ ${ }^{3}$ Teknik Mesin, Politeknik Kediri \\ ${ }^{4}$ Teknik Elektro, Institut Teknologi Nasional Malang \\ *Email Korespondensi: yohanes@lecturer.itn.ac.id
}

\begin{abstract}
ABSTRAK
Kopi adalah minuman dengan cara di seduh dengan air panas, ada beberapa jenis kopi yang tumbuh di wilayah Kab. Kediri yaitu kopi robusta dan lebrika. Berkaitan dengan hal pengabdian masyarakat yang dilakukan di Kab. Kediri yaitu transfer teknologi proses sangrai biji kopi untuk meningkatkan kualitas dan karakter yang dimiliki oleh kopi yang tumbuh di daerah gunung kelud agar memiliki citra rasa yang khas. Salah satu transfer teknologi yang dilakukan yaitu membuat mesin sangrai kopi untuk penyangrai kopi dengan pemanas kompor berbahan bakar LPG. Sangrai biji kopi sendiri di bedakan menjadi beberapa warna tergantung dari lama waktu sangrai dan temperatur yang digunakan pada saat sangrai biji kopi, semakin besar temperatur yang digunakan saat menyangrai kopi otomatis mempengaruhi waktu yang digunakan semakin sedikit untuk menyangrai biji kopi. Hasil dari sangrai terdapat 3 pilihan warna yang pertama light, kedua medium dan yang ke 3 dark. Dengan variasi temperatur $100{ }^{\circ} \mathrm{C}$ sampai dengan $220{ }^{\circ} \mathrm{C}$ begitu juga dengan lama waktu penyangraian mulai dari 10 menit sampai dengan 30 menit.
\end{abstract}

Kata kunci : kopi, temperature, LPG

\section{ABSTRACT}

Coffee is a beverage by brewing with hot water, there are several types of coffee that grow in the district. Kediri namely robusta and lebrika coffee. Related to community service conducted in the District. Kediri namely the transfer of roasted coffee bean technology to improve the quality and character of coffee grown in the Kelud mountain area in order to have a distinctive taste image. One of the technology transfers is to make a coffee roaster machine for roasting coffee with LPG fueled stove heaters. Roasted coffee beans themselves are differentiated into several colours depending on the length of time roasted and the temperature used when roasting coffee beans, the greater the temperature used when roasting coffee automatically affects the less time spent roasting coffee beans. The results of the roast there are 3 choices of the first colour light, the second medium and the third dark. With variations in temperature of $100^{\circ} \mathrm{C}$ up to $220^{\circ} \mathrm{C}$ as well as the roasting time was ranging from 10 minutes to 30 minutes.

Keywords: coffee, temperature, $L P G$

\section{PENDAHULUAN}

Kabupaten Kediri merupakan salah satu kabupaten yang ada di propinsi jawa timur yang memiliki potensi alam yang unik, dimana Kabupaten kediri diapit oleh dua gunung yang berbeda sifatnya, yaitu gunung kelud di sebelah timur yang bersifat vulkanik dan gunung wilis disebelah barat yang bersifat non vulkanik sehingga mempunyai citra rasa yang khas kopi dari daerah Kabupaten Kediri yang nantinya bisa memiliki nilai jual yang tinggi, karena berbeda dengan kopi yang lain hanya bisa ditemukan di wilayah Kediri dan bisa menjadikan salah satu produk unggulan Kabupaten Kediri bila dilakukan dengan proses yang benar. Karena kopi yang diambil dari batang harus yang benar-benar matang, bila ada yang masih belum matang akan mempengaruhi citra rasa dari kopi.

Hasil analisa lapangan di kabupaten kediri bahwa hasil kopi bisa ditingkatkan nilai penjualannya. Sehingga perlu untuk dikembangkan untuk mempunyai nilai jual yang tinggi 
ke pasar yang lebih luas, agar lebih dikenal diluar daerah. Sehingga diperlukan pengembangan potensi kopi di UKM wilayah Kediri. Dalam hal ini tentunya dibutuhkan proses produksi yang jeli. Dimulai pengupasan kulit buah kopi cara ini digunakan untuk memproses pengeringan biji kopi agar cepat kering karena langsung ke biji kopi, tidak lagi mengeringkan kulit biji kopi. Dari sini sudah banyak mempengaruhi citra rasa dari kopi. Selanjudnya dilakukan proses penyangraian kopi menggunakan alat penyangrai yang banyak macamnya, mulai dari tradisional sampai modern yang sudah menggunakan kontrol waktu dan temperatur dan masih banyak lagi yang menghasilkan citra rasa berbeda dari masingmasing proses yang sudah dilakukan (Ambarita, et al., 2017; Darshit \& Agawal, 2011; Djiwo \& Setyawan, 2016; Fudholi, et al., 2010).

Memang banyak parameter pada kopi agar menghasilkan citra rasa yang khas dan stabil. Pada pengabdian ini sudah dilakukan penyangraian atau lebih dikenal penggosengan. Dimana proses sebelumnya penyaraian menggunakan sistem penggorengan dengan wajan yang besar akan dirubah menjadi pemasakan dengan oven yang berputar agar lebih merata dengan dilengkapi sensor temperatur dan kontrol rpm untuk menghasilkan produk kopi yang unggul dan menyamakan citra rasa dalam setiap produksi. Hal ini dikarenakan pemasakan biji kopi dengan oven dapat meningkatan citra rasa yang ada pada kopi lebih stabil (Saravanakumar \& Mayilsamy, 2010; Setyawan, et al., 2017; Siagian, et al., 2017; Hii, et al., 2006). Sehingga telah dilakukan perubahan sistem masak biji kopi yang telah ditambahkan alat yang digunakan untuk mendinginkan kopi dengan cepat agar uap air tidak kembali masuk ke dalam kopi.

\section{METODE}

Dengan kegiatan pengabdian masyarakat ini beberapa hal yang dilakukan untuk menyelesaikan permasalahan-permasalahan yang telah dirumuskan yang berhubungan dengan teknologi tepat guna, dalam hal ini yaitu teknologi pengolahan biji kopi. Kopi bisa dimanfaatkan untuk minuman dengan cara di seduh dengan air panas, ada beberapa jenis kopi yang tumbuh di wilayah Kab. Kediri yaitu kopi robusta dan lebrika. Berkaitan dengan hal pengabdian masyarakat yang dilakukan di Kab. Kediri yaitu transfer teknologi proses sangrai biji kopi untuk meningkatkan kualitas dan karakter yang dimiliki oleh kopi yang tumbuh di daerah Gunung Kelud agar memiliki citra rasa yang khas. Salah satu transfer teknologi yang dilakukan yaitu membuat mesin sangrai kopi untuk penyangrai kopi dengan pemanas kompor berbahan bakar LPG seperti pada Gambar 1 dan 2.

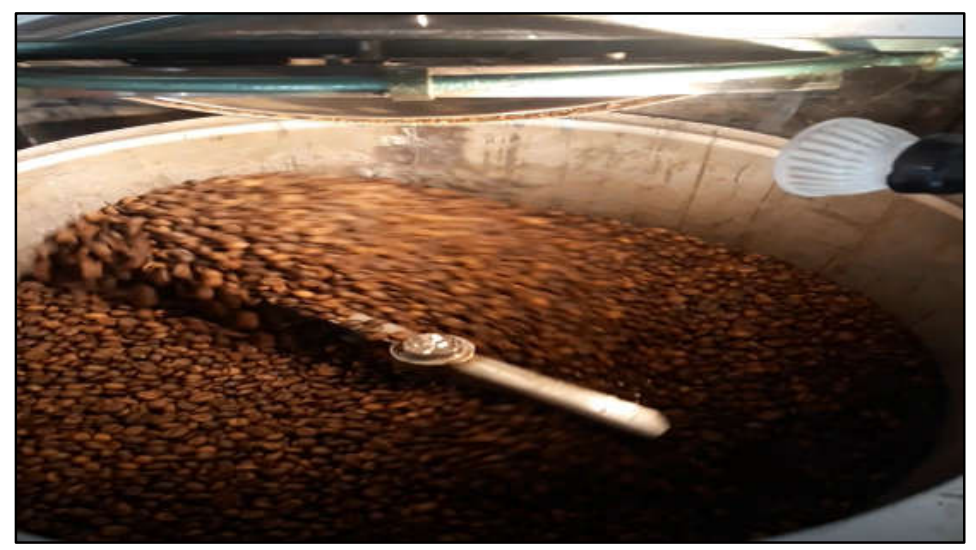

Gambar 1. Proses pendinginan biji kopi 


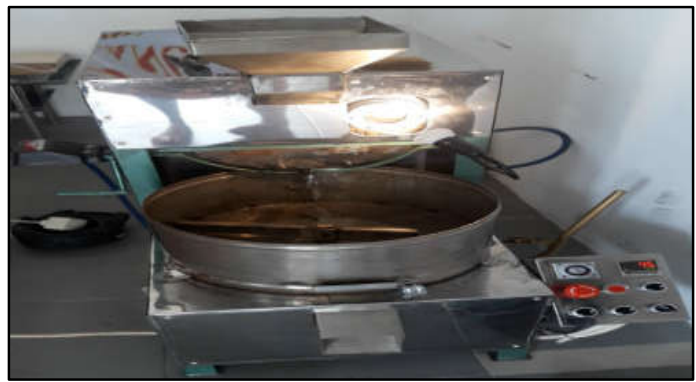

Gambar 2. Mesin sangrai biji kopi.

Lebih khusus lagi mesin sangrai kopi ini dengan cara sangrai berputar, dilengkapi tempat pendinginan kopi menggunakan pengaduk dengan sistem kopling agar uap air yang ada pada kopi tidak kembali lagi masuk ke dalam biji kopi yang sudah di sangrai. Mesin sangrai ini memiliki keunggulan tingkat kematangan kopi merata, efisien proses pengolahan kopi dan meminimalisir energi yang terbuang. Sangrai biji kopi sendiri seperti pada Gambar 3 di bedakan menjadi beberapa warna tergantung dari lama waktu sangrai dan temperatur yang digunakan pada saat sangrai biji kopi, semakin besar temperatur yang digunakan saat menyangrai kopi otomatis mempengaruhi waktu yang digunakan semakin sedikit untuk menyangrai biji kopi. Hasil dari sangrai terdapat 3 pilihan warna yang pertama light, kedua medium dan yang ke 3 dark.

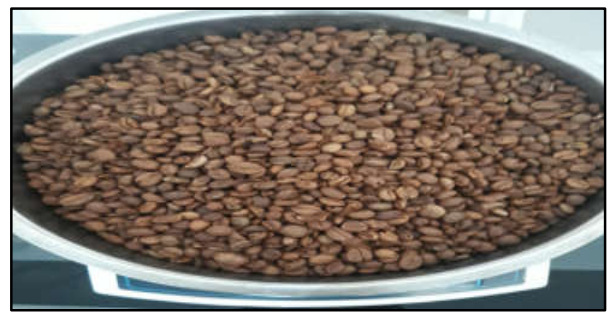

Gambar 3. Hasil sangrai biji kopi.

\section{HASIL DAN PEMBAHASAN}

Proses pengabdian masyarakat secara keseluruhan berjalan lancar karena bantuan dari mitra UKM kopi yang ada di Kab. Kediri, sehingga program pengabdian masyarakat tercapai sesuai tujuan. Dalam program ini mitra dala hal ini UKM kopi mempelajari kerja mesin sangrai kopi seperti mempraktekkan cara kerja dimulai dengan pengaturan temperatur 100 ${ }^{0} \mathrm{C}$ sampai dengan $220{ }^{\circ} \mathrm{C}$ bagaimana hasil kopi yang sudah di sangrai. Begitu juga mempelajari lama waktu penyangraian mulai dari 10 menit sampai dengan 30 menit hasinya akan berubah. Mitra dengan baik menerima arahan, mengikuti intruksi yang diberikan untuk mempelajari cara kerja mesin kopi dan melihat hasil dari mesin sangrai kopi yang sudah dilakukan selama pelatihan. Secara umum tujuan gegiatan program pengabdian masyarakat di UKM kopi Kab. Kediri bisa dikatakan berhasil, sudah sesuai dengan hasil yang diharapkan waktu survei.

Diantaranya mengatasi permasalahan yang dialami mitra yaitu, yang pertama diharapkan adanya mesin yang mempermudah dalam mensangrai biji kopi agar hasilnya terkontrol dan hal tersebut sudah terpenuhi oleh tim pengabdian masyarakat. Kedua bisa menjalankan mesin sangrai kopi dengan mudah tanpa harus membutuhkan tenaga khusus, hal tersebut juga sudah terpenuhi yaitu dengan cara memberi pelatihan secara langsung kepada mitra. Ketiga mitra bisa memperbaiki dan merawat alat sangrai kopi, hal tersebut juga sudah kami berikan pelatihan agar mitra bisa melakukan sendiri tanpa harus membawa ke bengkel bila kerusakkannya ringan. 
Dalam pembuatan mesin sangrai biji kopi dimulai dengan perancangan mesin secara sederhana yang dilakukan bersama mitra disaat melakukan survei. Mitra mengharapkan adanya mesin yang bisa menghasilkan kopi yang sama pada setiap produksi dan tidak terlalu sulit dalam perawatannya bisa dilakukan sendiri kalau bisa. Sehingga kami dengan tim dari Teknik Mesin yang fokus dalam bidang material bekerjasama dengan tim bidang konversi energi untuk merangcang mesin sangrai kopi, dalam hal ini perlu ditentukan material apa yang cocok untuk kopi agar tidak terkontaminasi dengan material yang digunakan. Sehingga dipilih menggunakan stenlis stell (Hii, et al., 2007; Hii, et al., 2011; Venkatesan \& Arjunan, 2014; Hossain, et al., 2011; Lamnatou, et al., 2012). Begitu juga tim konversi energi bagaimana cara sesingkat mungkin mengsangrai kopi tetapi tidak merusak tektur yang dimiliki biji kopi. Sehingga digunakan pemanasan menggunkan rotari agar panasannya rata dan temperatur yang digunakan maksimal $220{ }^{\circ} \mathrm{C}$, dengan menggunakan bahan bakar LPG.

Secara umum kerja alat sangrai kopi dilengkapi dengan pengaduk ditempat pendinginan menggunakan sistem kopling. Cara kerja alat sangrai kopi ini, sebelum memasukkan kopi kedalam tabung sangrai, setting temperature maksimal $220^{\circ} \mathrm{C}$ pada panel, kemudian pemanas akan menyala dan menghidupkan motor penggerak untuk menggerakkan tabung sangrai. Tabung sangrai ini berfungsi sebagai ruang pesangraian kopi. Setelah tabung sangrai telah mencapai temperature tersebut, kopi dimasukkan kedalam tabung sangrai melalui chopper. Selama penyangraian, kopi didalam tabung bergerak secara terus menerus dikarenakan dinding dalam tabung sangrai berbentuk ulir. Dengan model seperti ini panas yang terjadi pada tabung sangrai dapat merata, karena panas tidak terpusat di satu titik pada dinding luar tabung, sehingga perpindahan panas yang terjadi panas merambat kedalam menuju kopi. sistem kerja tabung sangrai ini digerakkan oleh motor penggerak dengan penghubung rantai. Tujuan menggunakan rantai karena terbuat dari logam baja paduan sehingga mampu menahan panas. Gerakan putar dari motor penggerak dihubungkan ke reducer menggunakan V-Belt. Reducer digunakan untuk memperlambat putaran. perbandingan reducer menggunakan perbandingan 30:1.

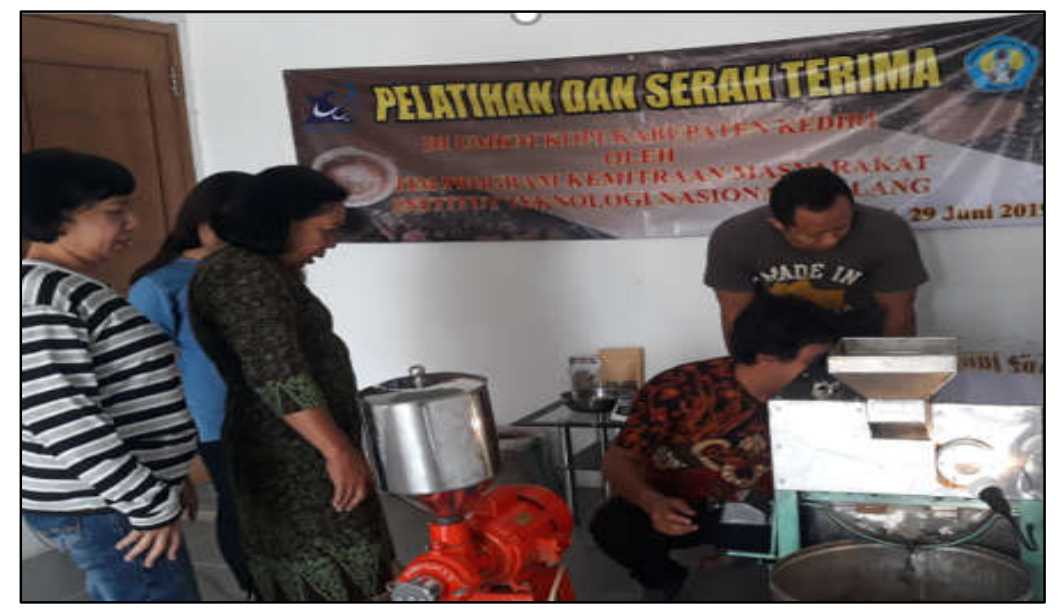

Gambar 4. Pelatihan dan serah terima alat sangrai kopi

Setelah proses penyangraian, dilanjutkan proses pendinginan ditempat pendinginan. Langkah awal menekan tuas kopling sehingga pengaduk dapat berputar. Kopi dari tabung sangrai masuk kedalam tempat pendinginan, kopi digerakkan dengan pengaduk selama 5 menit kemudian penutup chopper keluar dibuka, kopi selesai diproses penyangraian. Cara kerja pengaduk pada tempat pendinginan berputar, digerakkan oleh motor penggerak. Motor penggerak berputar dihubungkan ke reducer menggunakan $V$-Belt. Hubungan antara motor 
penggerak dengan reducer ditambahkan sistem kopling. Kopling inilah yang berfungsi memutus atau menyambungkan putaran motor penggerak ke reducer. Dengan cara menekan tuas kopling maka kopling bergerak maju menyambung pada as reducer, sehingga as reducer akan berputar. Putaran as reducer ditransmisikan ke pengaduk sehingga pengaduk akan bergerak. Perbandingan putaran pada reducer ini menggunakan 30:1. Pelatihan pemakaian alat kepada mitra dapat dilihat pada Gambar 4.

\section{DAMPAK DAN MANFAAT}

Dampak maupun manfaat yang didapatkan oleh mitra pengabdian masyarakat yaitu mendapatkan pelatihan cara meningkatkan kualitas produksi biji kopi menggunakan mesin sangrai kopi dengan sistem pemanasan rotari atau sistem putar agar biji kopi bisa matang secara rata dan singkat, menggunakan bahan bakar LPG karena mudah untuk didapat dan juga bisa dengan mudah untuk dipindahkan. Mesin sangrai biji kopi ini juga dilengkapi dengan proses pendingin sistem putar, yang digunakan untuk melepas uap panas ke udara agar tidak masuk lagi ke dalam biji kopi yang sudah di sangrai, bila itu terjadi kualitas kopi akan menurun karena tidak tahan lama akan muncul jamur dan bau-bau yang tidak diharapkan karena peningkattan kadar air yang ada di biji kopi.

Selain itu mitra juga mendapatkan pelatihan cara pengemasan yang baik, dalam hal ini yang dimaksud kemasan yang baik kemasan tertutup secara rapat sehingga tidak terkontaminasi oleh faktor lingkungan yang dapat meningkatkan kadar air yang ada di dalam biji kopi yang sudah di sangria seperti pada Gambar 5. Kemasan yang digunakan dapat dilihat di gambar 5a-b. kemasan tersebut terlihat transparan, sehingga terlihat kopi yang ada dilamnya seperti warna kopi light, medium dan dark. Sehingga konsumen bisa memilih dan tertarik membeli kopi, karena terlihat hasil sangrai yang gelap apa yang terang tergantung selera konsumen. Karena masing-masing hasil sangrai memiliki citra rasa yang berbeda tergantung dari warnanya.

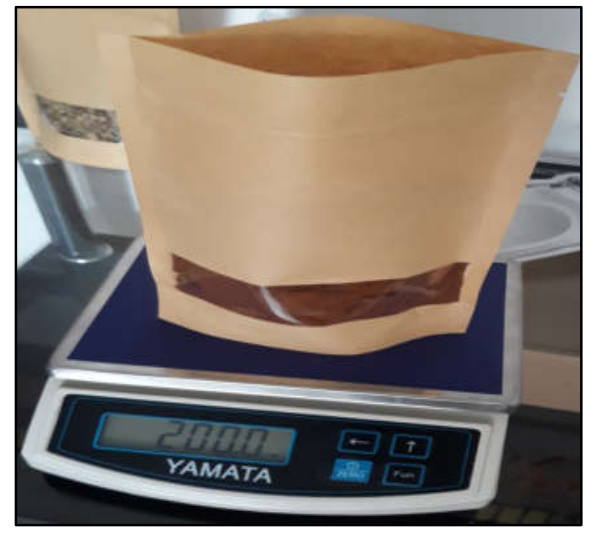

a

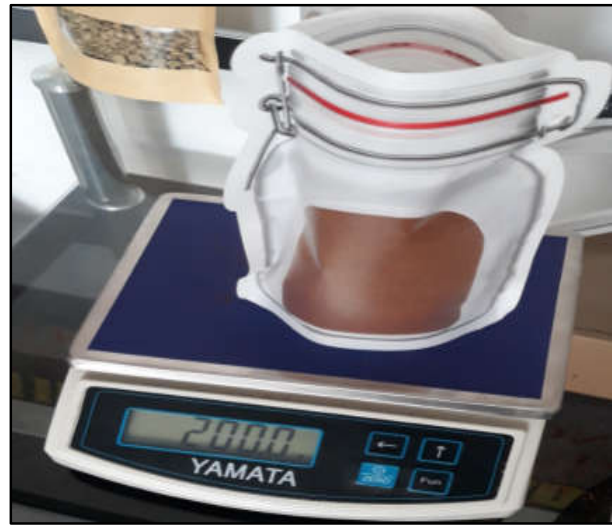

b

Gambar 5.a. Proses pengemasan menggunakan kertas yang dilapisi dengan lapisan tipis plastik., b. Proses pengemasan menggunakan plastik transparan.

\section{KESIMPULAN}

Dari hasil pengabdian masyarakat yang sudah dilakukan bersama tim. Mitra sangat antusias menjalakan program selama kegiatan berlangsung. Secara keseluruhan program pengabdian kepada masyarakat di Kab. Kediri khususnya UKM kopi berjalan dengan baik dan lancar sampai dengan akhir. Mesin yang sudah diberikan mesin sangrai biji kopi sistem rotari atau putar dilengkapi dengan sistem pendinginan biji kopi. Mesin yang diberikan sudah berjalan dan tidak ada kendala selama pelatihan baik cara kerja mesin sangrai kopi maupun proses pemeliharaan masin sangrai kopi sampai perbaikan mesin klo ada kerusakan 
dikemudian hari. Mitra sangat aktif berdiskusi mengenai mesin sangrai biji kopi sambil melakukan praktek pada mesin sangrai biji kopi serta meningkatkan kualitas kopi agar mempunyai citra rasa yang khas gunung kelud yang dimiliki Kab. Kediri

\section{REFERENSI}

Ambarita, H., Setyawan, E. Y. dan Nasution, H. (2017) 'Optimasi Mesin Sabut Kelapa Dan Gagang Kayu di Kabupaten Serdang Bedagai Sumatra Utara', Seminar Nasional dan Gelar Produk 2017, Universitas Muhamadiyah Malang, Indonesia 1202-1212

Darshit, P. dan Agawal, G. D. (2011) 'Solar Drying in Hot and Dry Climate of Jaipur, India', International Journal of Renewable Energy Research, 1(4): 224-231

Djiwo, S. dan Setyawan, E. Y. (2016) 'Mesin Teknologi Tepat Gunasabut Kelapa di UKM Sumber Rejeki Kabupaten Kediri', Seminar Nasional dan Gelar Produk 2016, Universitas Muhamadiyah Malang, Indonesia 576-582

Fudholi, A., Sopian, K., Ruslan, M. H., Alghoul, M. A. dan Sulaiman, M.Y. (2010) 'Review of Solar Dryer for Agricultural and Marine products', Renewable and Sustainable Energy Reviews, 14: 1-30.

Saravanakumar, P. T. dan Mayilsamy, K. (2010) 'Forced Convection Flat Plate Solar Air Heaters With and Without Thermal Storage', Journal of Scientific and Industrial Research, 69: 966-968.

Setyawan, E. Y., Djiwo, S. dan Sugiarto, T. (2017) 'Simulation Model of Fluid Flow and Temperature Distribution in Porous Media Using Cylinder Convergent and Divergent Nozzle', International Journal of Technology And Sciences.

Siagian, P., Setyawan, E. Y., Gultom, T., Farel H. dan Himsar A. (2017) 'A Field Survey on Coffee Beans Drying Methods of Indonesian Small Holder Farmer', $1^{\text {st }}$ Nommensen International Conference on Technology, IOP Conference on Technology and Engineering, IOP Conf. Series: Materials Sciences and Engineering.

Hii, C. L., Abdul Rahman, R., Jinap, S. dan Che Man Y. B. (2006) 'Quality of cocoa beans dried using a direct solar dryer at different loadings', Journal of Science of Food and Agriculture. (86). 1237-1243.

Hii, C. L. (2007) 'Quality comparison of cocoa beans dried using solar and sun drying with perforated and non-perforated drying platform', The Proceedings of the $5^{\text {th }}$ Asia-Pacific Drying Conference. 546 - 552.

Hii, C. L., Law C. L., Cloke M. dan Suzannah S. (2011) 'Improving Malaysian cocoa quality through the use of dehumidified air under mild drying conditions', Journal of Science of Food and Agriculture. (91). 239-246.

Venkatesan, N. dan Arjunan, T.V. (2014) 'An Experimental Investigation and Performance Analysis of a Solar Drying of Bitter Gourd Using an Evacuated-Tube Air Collector', International Journal of Chem Tech Research, 6(14). 5510-5518.

Hossain, M. S., Saidur, R., Fayaz, H., Rahim, N. A., Islam, M. R., Ahamed, J. U. dan Rahman, M. M. (2011) 'Review on Solar Water Heater Collector and Thermal Performance of Circulating Pipe', Renewable and Sustainable Energy Reviews, 15. 3801-3812.

Lamnatou, C., Papanicolaou E., Belessiotis V. dan Kyriakis, N. (2012) 'Experimental Investigation and Thermodynamic Performance Analysis of a Solar Dryer Using an Evacuated-Tube Air Collector', Applied Energy, 94. 232-243. 